\title{
Relações Internacionais: o estado da disciplina
}

International Relations: the state of the discipline

Relaciones Internacionales: el estado de la disciplina

Felipe Leal Albuquerque ${ }^{1}$

DOI: 10.5752/P.1809-6182.2021v18n1pX

Recebido em: 09 de setembro de 2020

Aceito em: 15 de março de 2021

\begin{abstract}
Resumo
Ao longo de quase um século de desenvolvimento das Relaçōes Internacionais, alunos e acadêmicos deparam-se com uma variedade de campos teóricos, métodos e temas de pesquisa. Este artigo resume a evolução histórica da disciplina, aponta os principais métodos utilizados e identifica debates contemporâneos, buscando auxiliar estudantes recém-ingressos no curso.

Palavras-chave: Relaçóes Internacionais. Teoria das Relaçóes Internacionais. Metodologia
\end{abstract}

\begin{abstract}
Students and academics have come across various theoretical fields, methods and research topics over the course of the last century, when International Relations developed. With the aim to support new students of the discipline, this article summarizes its historical evolution, indicates the main methods used and identifies the contemporary debates.
\end{abstract}

Keywords: International Relations. International Relations Theory. Methodology.

\section{Resumen}

En el transcurso de casi un siglo de desarrollo de las Relaciones Internacionales, estudiantes y académicos tienen a disposición variados campos teóricos, métodos y temas de investigación. Este artículo resume su evolución histórica, señala los principales métodos e identifica los debates contemporáneos, buscando ayudar a los nuevos estudiantes del curso. Palabras clave: Relaciones Internacionales. Teoría de las Relaciones Internacionales. Metodología

\footnotetext{
1 Especialista (PUC-Rio, 2009) e mestre (UERJ, 2013) em Relaçôes Internacionais e doutor em Ciência Política pelo Instituto de Ciências Sociais da Universidade de Lisboa (ICS-UL, 2020). Foi Marie Curie Fellow (2014-2017) do programa da Comissão Europeia "Power and Region in a Multipolar Order (PRIMO-ITN)" e professor colaborador do mestrado em Ciência Política da Universidade de Salamanca. Em 2016, foi Doctoral Researcher na Universidade de Stellenbosch, na África do Sul, e no German Institute of Global and Area Studies (GIGA), em Hamburgo. Foi professor substituto de Política Internacional do IFCS-UFRJ e assistente de pesquisa no Centro de Pesquisa e Documentação de História Contemporânea do Brasil da Fundação Getúlio Vargas (CPDOC-FGV), também tendo atuado na Agência da ONU para Refugiados (ACNUR). Seus principais interesses são análise de política externa e processo decisório, métodos qualitativos e regimes multilaterais (especialmente mudança do clima, segurança alimentar, paz e segurança internacionais e migraçóes).
} 


\section{O que são as Relações Internacionais?}

Relações Internacionais é a disciplina vertente da Ciência Política que visa ao estudo das interações políticas, econômicas e sociais que se realizam principalmente entre Estados, mas também entre esses e atores como organizaçôes internacionais, empresas, organizaçóes não governamentais (ONG), grupos terroristas e narcotraficantes, indivíduos, entre outros. Em outras palavras, a disciplina de Relaçóes Internacionais (com letra maiúscula) inquire sobre as relaçôes internacionais (com letra minúscula). Entre seus objetivos, estão o entendimento de eventos passados, a compreensão do contexto hodierno e o diálogo interdisciplinar com a História, a Economia, o Direito, a Sociologia e a Antropologia.

Em virtude dessa amplitude, a disciplina de Relaçôes Internacionais envolve variadas abordagens ontológicas, epistemológicas e metodológicas. Devido a sua versatilidade, a disciplina influencia tomadores de decisões tanto no que diz respeito à promoção da cooperação entre os povos quanto à maximização do poder estatal. O objeto de estudo das Relaçôes Internacionais está num estado de constante interação entre as relaçóes estratégico-diplomáticas dos Estados e os vários tipos de transações pertinentes a um mundo cada vez mais globalizado (BROWN; AINLEY, 2009).

Burchill e Linklater apontam seis dimensões para a compreensão das dinâmicas internacionais: (i) as relaçôes entre os Estados, tradicionalmente centrais para o campo de estudo, e os outros atores; (ii) as relaçôes entre as grandes potências e os laços de ascendência dessas sobre as naçôes em desenvolvimento; (iii) questôes empíricas, que não somente envolvem a distri- buição de poder militar, domínio territorial e tamanho das economias, mas temas como direitos humanos, mudanças climáticas e saúde global; (iv) discussões éticas, a exemplo de justificaçôes para intervençôes humanitárias; (v) disputas metodológicas sobre a natureza das Ciências Sociais e a adequação da análise positivista; e, finalmente, (vi) a interdisciplinaridade como instrumento de compreensão de fenômenos internacionais (BURCHILL; LINKLATER, 2005).

\section{Quais são os "grandes debates"?}

No decurso da história, os agrupamentos humanos estabeleceram relaçôes com as comunidades vizinhas através da prática do comércio, da diplomacia e da guerra. A este respeito, Tucídides descreveu, no século $\mathrm{V}$ a.C., o conflito entre Atenas e a vitoriosa Esparta para racionalizar sobre o uso da guerra como instrumento de poder estatal. Nicolau Maquiavel defende, no século XVI, a moralidade diferenciada do líder e enfatiza o imperativo de sobrevivência do Estado. Thomas Hobbes completa, um século mais tarde, a base de pensamento do realismo, campo teórico visto mais à frente, ao argumentar a inexistência de autoridade com monopólio do poder legítimo do uso da violência em âmbito internacional.

Somente no século XVIII é que se começa a olhar para as relaçóes entre coletividades com base nas prerrogativas dos Estados nacionais, então em processo de formação, graças a filósofos como Jean-Jacques Rousseau e Immanuel Kant, que, juntamente com John Locke e John Stuart Mill, compóem os alicerces do pensamento liberal da disciplina. Já o termo "Relações Internacionais" surge com Jeremy Bentham em 1789. 
As Relaçóes Internacionais ganham estatura de disciplina acadêmica com a fundação, em 1919, do departamento de Política Internacional da Universidade de Aberystwyth, no País de Gales. Ainda com o mundo sob o trauma da Primeira Guerra Mundial, a nova disciplina foi inspirada pelo ideário do presidente norte-americano Woodrow Wilson e teve por propósito inicial o desenvolvimento de estudos sobre guerra e paz, bem como de instrumental teórico que pudesse evitar novos conflitos. A escola diplomática Edmund A. Walsh da Universidade de Georgetown e a London School of Economics, situadas nos Estados Unidos e no Reino Unido, também fazem parte dos esforços iniciais de configuração de uma disciplina organizada, mais tarde estudada em outras instituiçôes europeias e norte-americanas. Para além do interesse acadêmico, portanto, o avanço das Relaçóes Internacionais como disciplina ocidental estava diretamente relacionado aos interesses político-estratégicos desses países. Com o tempo, a disciplina passa a ganhar maior escopo temático e diversidade.

A evolução das Relaçôes Internacionais é marcada por quatro grandes debates, caracterizados pelo diálogo entre distintas correntes teóricas. Essas teorias têm como objetivo principal constituir métodos e conceitos que permitam explicar e entender a ocorrência de determinados fenômenos. É possível inferir as teorias como "lentes" através das quais o analista busca perceber o contexto abstrato que o cerca e os conceitos daí derivados como meios de operacionalização da realidade. Por sua própria amplitude e interdisciplinaridade, a disciplina aborda uma pluralidade de aspectos que vão desde o equilíbrio de poder e o estudo da guerra até discussóes sobre agentes, estruturas e preferências individuais. Paradoxalmente, a riqueza teórico-conceitual das Relaçóes Internacionais dificulta o estabelecimento de denominadores comuns e de pontos de contato que perpassem todos os momentos de evolução da disciplina.

O primeiro grande debate (i) dá-se entre o realismo e o liberalismo, as correntes teóricas fundacionais das Relaçôes Internacionais. Concomitante ao momento que vai de 1919 a 1939 ao período imediatamente posterior à Segunda Guerra Mundial, o debate centrou-se em divergências ontológicas. A abordagem realista parte de uma leitura pessimista da natureza humana e tem como premissas a centralidade de Estados unitários e "racionais"; a ausência de Leviatã em ambiente internacional anárquico, o que faz com que cada Estado objetive ampliar a sua segurança em relação aos demais; e a busca pela sobrevivência. Medo, prestígio, guerra e a procura de garantir o "interesse nacional" determinam o comportamento estatal. Entre os variados modelos de análise do realismo, destaca-se o "dilema do prisioneiro", uma ilustração da teoria dos jogos que denota como a ausência de informaçóes claras e a desconfiança mútua podem impedir a cooperaçáo. Edward Carr, Hans Morgenthau, Raymond Aron e Kenneth Waltz são os principais expoentes dessa vertente teórica.

A tradição liberal, por sua vez, advém da contribuição de teóricos contratualistas europeus do século XVIII, preocupa-se com as relaçóes entre indivíduos, sociedades e governos e pondera como essas podem afetar a vida internacional. A existência de governos democráticos e a interdependência gerada pelo livre comércio contribuem para a consecução da "paz perpétua" entre os Estados (KANT, 2003). Além disso, para autores como Norman Angell, Alfred Zimmern e o próprio Woodrow 
Wilson sociedades podem autorregular-se por meio de instituiçóes, o que garantiria regras mínimas de convivência entre os Estados e evitaria o surgimento de ameaças. A realizaçáo de interesses individuais levaria, pois, a ganhos coletivos. O pensamento liberal é qualificado de "idealista" pelos teóricos realistas e perde força com o início das hostilidades que levaram à Segunda Guerra Mundial. A sua influência, no entanto, é perceptível com o estabelecimento das Naçóes Unidas, a evolução do Direito Internacional e a aplicação do princípio de autodeterminação dos povos.

O pensamento liberal também influencia a teoria funcionalista, que advoga pela integraçáo e pela governança coletiva como formas de superação de discórdias. A importância do funcionalismo é renovada com os escritos de Ernst B. Haas. Principal expoente do neofuncionalismo nos anos 1950 e 1960, o autor defendia que a integração regional em áreas específicas - como a economia - dinamizaria, por meio de um processo de "spill-over", as possibilidades de cooperação em outros setores (E. HAAS, 1958). O atingimento da paz ocorreria por meio da constituição de agências especializadas e organismos internacionais - por exemplo, a Comunidade Europeia do Carvão e do Aço que assumiriam funçôes até então exclusivas dos Estados.

O segundo grande debate (ii) ocorre entre os tradicionalistas, como eram comumente chamados os realistas e liberais, e os behavioristas, inspirados pelas ciências naturais. Nos anos 1950 e 1960, a "revolução" behaviorista define as abordagens clássicas como demasiado normativas e propóe mudanças metodológicas. Com foco em análises quantitativas, na procura de conclusóes "generalizáveis" e baseado no positivismo, o behaviorismo trata a ciência como algo neutro e técnico, de modo que fenômenos sociais deveriam ser explicados individualmente e testados de forma empírica. Se, para autores como os da Escola de Frankfurt o behaviorismo era uma abordagem conservadora e reducionista, para outros representou um modo de avançar a produção de conhecimento de acordo com parâmetros replicáveis e dotados do rigor científico. O behaviorismo teve influência na evolução metodológica das Relaçóes Internacionais, notadamente na academia norte-americana.

$\mathrm{O}$ terceiro grande debate (iii) retoma o primeiro. Faz referência à reedição da disputa entre realismo e liberalismo, atualizados como neorrealismo e neoliberalismo. $\mathrm{O}$ contexto era o dos anos 1970, quando ocorria a détente entre Estados Unidos e União Soviética. A teoria realista não conseguiu prever e tampouco forneceu ferramentas analíticas que explicassem satisfatoriamente o porquê do colapso da União Soviética. Além disso, não abrangia a multiplicidade de atores internacionais que operavam por meio do Estado e à margem dele, como organizaçôes não governamentais (ONG), organizaçôes internacionais e empresas. Já os liberais precisavam superar a imagem de serem demasiado idealistas e distantes do fato de que o tabuleiro internacional era também palco de jogos de força entre as grandes potências.

Neoliberais (também conhecidos como institucionalistas neoliberais) como Joseph Nye e Robert Keohane enfatizam a relevância de atores não estatais e afirmam que problemas econômicos, políticos e sociais não são somente causados pelo comportamento dos Estados ou plenamente controlados por esses (KEOHANE; NYE JR., 1977). Ainda que permanecesse importante, o poder militar era complementado pelas conexóes entre socieda- 
des, aumento dos fluxos transnacionais e amplitude das temáticas internacionais. Em concessão ao pensamento realista, os neoliberais reconhecem a existência da anarquia em nível sistêmico. No entanto, por estarem interdependentes em ambiente anárquico, os Estados buscariam implementar canais de cooperação, estabelecer instituições e tratados e limitar a possibilidade de conflito. Ao contrário da visão realista, que considera as instituiçóes internacionais como reflexos da distribuição de poder entre os estados e subprodutos da ação desses, a vertente neoliberal observa-as como mecanismos de coordenação que têm poder de agência e minimizam os jogos de soma zero e o "dilema do prisioneiro". Organizaçóes internacionais, portanto, para a promoção de parâmetros mínimos para a regulação da vida internacional. A influência do neoliberalismo também é perceptível na obra de autores como John Ruggie, que desenvolve o conceito de multilateralismo.

Posteriormente, a matriz liberal expande seu escopo teórico com a incorporação de novas perspectivas provenientes, por exemplo, da Sociologia e da História, e amplia o diálogo com a escola construtivista. Os estudos sobre paz e segurança internacionais são renovados, com especial enfoque em temas como intervencionismo humanitário e uso da força e o papel de instituições internacionais e regionais no pós-Guerra Fria. Em contínuo debate com autores realistas, trabalhos como os de John Ikenberry reafirmam a resiliência da ordem liberal estabelecida pelos Estados Unidos e minimizam o declínio relativo de Washington. Já Joseph Nye reinterpreta concepçóes sobre poder com os conceitos de soft e smart power.

O neorrealismo (ou realismo estrutural) reforça cânones realistas clássicos, como a centralidade estatal, a desconfiança mútua e a anar- quia. Destaca, no entanto, a influência do sistema internacional como variável chave. $\mathrm{O}$ foco está na estrutura e não em atores individuais, não sendo relevante a realidade doméstica dos Estados. Em obra paradigmática, Kenneth Waltz argumenta que o sistema internacional é definido pela distribuição de capacidades (WALTZ, 2010). Como bolas de uma mesa de bilhar, os Estados têm seu comportamento limitado pela estrutura. Mudanças, quando ocorrem, são raras e confinadas à configuração anárquica ou hierárquica. Também referência no campo neorrealista, Robert Gilpin discute como mudanças sistêmicas dependem da atuação do Estado hegemônico e da concentração de poder desse frente aos demais.

$\mathrm{O}$ realismo ganha diversidade nos anos 1990 com o surgimento de derivaçôes conhecidas como realismo ofensivo e realismo defensivo, desenvolvidas por nomes como John Mearsheimer. Ademais, é possível distinguir outra vertente recente do realismo, conhecida como realismo neoclássico, associada a Fareed Zakaria e Gideon Rose. Diferentemente do neorrealismo, o realismo neoclássico faz concessões ao campo liberal e inclui o nível de análise doméstico como essencial para a compreensão das decisões estatais.

Apesar das diferenças, neorrealismo e neoliberalismo aproximam-se na importância conferida à variável sistêmica como princípio orientador, ao positivismo como teoria filosófica e aos Estados como entidades mais relevantes. Essa proximidade levou autores como Ole Waever (1996, p. 161) a dizer que o debate era artificialmente construído, inventado por conta de propósitos ilustrativos e didáticos. $\mathrm{Na}$ mesma direção, Robert Keohane e Lisa Martin (1999, p. 3) afirmam que os dois campos teóricos são "meios-irmãos". 
O debate entre o neorrealismo e o neoliberalismo influencia o desenvolvimento da teoria de regimes e da Escola Inglesa. Regimes referem-se a normas, princípios, regras e processos decisórios por meio dos quais as expectativas estatais convergem quanto a uma determinada área temática. Ainda que mais próxima da perspectiva neoliberal, a teoria de regimes também atraiu a atenção de autores mais próximos do realismo, como Susan Strange e Joseph Grieco.

A Escola Inglesa tem como principais expoentes Hedley Bull, Adam Watson e Martin Wight e apresenta-se como uma via media entre as correntes realista e liberal. Inspirada pelo estudo da história e pelo "racionalismo" de Hugo Grotius, um dos precursores do Direito Internacional, a Escola Inglesa tem perspectiva evolucionista das Relaçôes Internacionais. Os Estados fazem uso de, portanto, interesses, valores, regras, instituiçôes, normas e práticas compartilhados que possibilitam o convívio cooperativo e a moderação da anarquia, o que Adam Watson define como "raison de système" (WATSON, 1992, p. 14). Conceitos como ordem e justiça são centrais para a Escola Inglesa e dialogam com concepçóes de sociedade internacional que Hedley Bull nomeou "pluralista" e "solidarista". A corrente teórica ganhou novas interpretaçôes a partir de autores como Barry Buzan, Edward Keene e Andrew Hurrell que discutem, por exemplo, a integração de países não-ocidentais e o papel de regiôes na sociedade internacional criada pelo Ocidente.

O construtivismo torna-se uma das principais escolas de pensamento das Relaçôes Internacionais na transição das décadas de 1980 e 1990. Considera a realidade como socialmente construída por atores e estruturas, de modo que não há antecedência ontológica entre eles (ONUF, 1989). Para Nicholas Onuf, por exemplo, a linguagem é o meio pelo qual interpretam-se e estabelecem-se as relaçóes entre indivíduos e sociedades, produzindo atos de fala e tendo impactos na prática política. Atores, como é o caso dos Estados, agem não apenas no contexto de, mas também sobre as instituiçóes/estruturas, o que faz com que o construtivismo rejeite condiçôes pré-determinadas e privilegie a mudança. Ideias, valores e crenças atribuem significado ao mundo material, o que ajuda a esclarecer as várias formas de comportamento estatal e de configuraçóes sistêmicas. Por isso, Estados que compartilham características comuns, como forma de governo ou modelo econômico, tendem a ver-se de modo positivo (WENDT, 1987).

Para além desses elementos unificadores, é possível dizer que o construtivismo se divide em vertentes mais próximas das teorias tradicionais e em abordagens mais pluralistas. Autores como Alexander Wendt, Martha Finnemore, Kathryn Sikkink e Peter Katzenstein fazem parte do primeiro grupo. Em geral, eles mantêm as mesmas bases epistemológicas e metodológicas das teorias de matriz realista e liberal e dialogam criticamente com o campo mainstream da disciplina. Essa tentativa de criação de canais de diálogo e de manutenção de aparência "científica" é questionada por autores como Richard Ashley, Michael Shapiro e R. B. J. Walker, considerados por realistas e liberais como radicais e associados ao pós-estruturalismo por negarem a existência de teorias neutras e por defenderem a inclusão de múltiplas narrativas na construção do conhecimento e de temas como subjetividade, relativismo, intertextualidade e culturas de resistência e de emancipação. Autores clássicos como Michel Focault, Jacques Derrida e Pierre Bordieu influenciam os escritos pós-estruturalistas. 
A dificuldade das teorias tradicionais de explicarem o fim da Guerra Fria abriu espaço não só para a organização do pensamento pós-estruturalista, mas também para abordagens como a da teoria crítica. A teoria crítica mantém a importância do caráter estrutural das Relaçóes Internacionais, partindo de fundamentos do marxismo e das ideias de Antonio Gramsci e da Escola de Frankfurt para analisar e propor mudanças emancipatórias. A teoria crítica dialoga com o materialismo da teoria de sistema-mundo ${ }^{2}$ de Immanuel Wallerstein e da teoria da dependência de Fernando Henrique Cardoso e Enzo Falleto e preserva conteúdos como mecanismos de dominação e de exclusão e relaçóes de dependência como neoimperialismo e neocolonialismo. Teóricos críticos como Robert Cox e Andrew Linklater propóem que o conhecimento seja repensado a partir de contribuições sociológicas, antropológicas, filosóficas e psicológicas.

O quarto grande debate das Relaçôes Internacionais (iv) está centrado na disputa metodológica e epistemológica entre positivistas e pós-positivistas, aqui incluídas as experiências teóricas do pós-estruturalismo, ambientalismo, ${ }^{3}$ pós-modernismo, ${ }^{4}$ teoria crítica e de abor-

2 A teoria de Wallerstein observa o mundo como sistema social no qual há uma divisão territorial do trabalho hierarquizada em centro, semiperiferia e periferia e estabelecida de acordo com relaçốes de produção. Tem relação direta com a teoria de dependência, abordagem teórica neomarxista que explica as relaçóes desiguais entre centro e periferia como reprodutoras do subdesenvolvimento.

3 A teoria ambientalista, também conhecida como "green theory", tem por base discussóes sobre meio ambiente e caráter interdisciplinar, englobando de perspectivas próximas ao institucionalismo neoliberal até visôes críticas ao sistema capitalista como um todo e ao modo como estados e atores internacionais operam e agem frente a problemas de ação coletiva, advogando pela descentralizaçáo de estruturas de poder.

4 Como matriz teórica, o pós-modernismo questiona as bases pretensamente racionais, científicas e delimitadas no tempo e no espaço das relaçóes internacionais, buscando ultrapassar limites disciplinares e desconstruindo visóes tradicionais. Autores como James Der Derian defendem que teorias individuais são incapazes de explicar a complexidade dagens do feminismo. 5 Divide, de um lado, autores "racionalistas", que buscam fatos observáveis e que são afeitos ao positivismo como método científico e, de outro, os "reflexivistas", ou refratários ao paradigma metodológico dominante por considerarem-no superficial e predeterminante. Os pós-positivistas refutam a existência de uma "realidade objetiva", acreditam que valores e intencionalidade não podem ser dissociados da produção do conhecimento e, por essa razão, buscam desenvolver estudos que incluam a visão do "outro". Obras que abordem lentes de gênero, classe e raça (CHOWDHRY; NAIR, 2004; TICKNER, 1992), além de modelos de análise alternativos, são privilegiados pelos pós-positivistas.

\section{Quais são os métodos utilizados?}

Afora as discussóes teóricas e epistemológicas, a evolução das Relaçôes Internacionais envolve o debate entre diferentes abordagens metodológicas. Em termos gerais, é possível identificar as tradições metodológicas quantitativa e qualitativa como as principais no campo de estudos das Relaçôes Internacionais.

das relaçôes internacionais, especialmente em circunstância marcada por maior interpenetração e porosidade de limites e fronteiras institucionais. Para Richard Devetak, conceitos como o de soberania estatal são anacrônicos e funcionam como profecias autorrealizáveis, devendo abrir espaço para a temas como diversidade étnica, multiculturalismo, e o papel de grupos indígenas e minorias.

5 As abordagens feministas têm em comum o uso do gênero como categoria de análise, a partir da afirmação do gênero como identidade socialmente construída e passível de perpetuar desigualdades, hierarquias e opressōes, visto que é sujeita a disputas de poder. Ponto comum entre as abordagens feministas é a ideia de que as correntes teóricas tradicionais ignoraram as discussóes sobre gênero e sua dimensão política. Além disso, autoras como Lori Handrahan trazem a relevância de visóes interseccionais que incluem debates sobre raça, classe e etnia. Essas agendas transbordam para temas como, por exemplo, construção da paz e situaçóes de pós-conflito, estudados por nomes como Cynthia Enloe. 
A tradição quantitativa envolve, como exemplos mais comuns, o método estatístico (inclui-se a análise bayesiana) e o método experimental. ${ }^{6}$ Baseia-se na aplicação de técnicas e raciocínio das ciências naturais, do uso da matemática e de softwares de pesquisa quantitativa. Insere-se, portanto, na corrente filosófica do positivismo. Entre seus objetivos estão o teste de hipóteses, o estabelecimento de padróes, a manipulação de variáveis e, no caso do método experimental, o uso de grupos de controle. Faceta comum do método quantitativo é o exame de grande quantidade de casos (Large- $N$ ).

A tradição metodológica qualitativa encontra-se tanto no campo do positivismo quanto no do pós-positivismo. No que diz respeito a métodos qualitativos positivistas usados nas Relaçóes Internacionais, cita-se o process-tracing e o método comparativo. O process-tracing vale-se da reflexão quantitativa sobre o teste de hipóteses para aplicá-la à análise qualitativa de um caso específico (within-case analysis) (BEA$\mathrm{CH}$; PEDERSEN, 2013). Analistas buscam observar como fatores explicativos e resultados (outcomes) estão inter-relacionados pela existência de mecanismos causais. O "caminho" entre fatores e resultados é identificado por meio de técnicas de recolha de dados como entrevistas e trabalho de arquivo. Já o método comparativo pretende comparar mais de um caso (small- $N$ ) a partir das suas variáveis e/ou resultados. Ambos os métodos são úteis para a identificação e o desenvolvimento de novas hipóteses e teorias ${ }^{7}$.

Mais recentemente, esforços têm sido envidados para aproximar as tradiçóes quantitativa e qualitativa do campo positivista. Sáo

6 A análise bayesiana utiliza-se da estatística para responder perguntas de pesquisa que tenham por base o estudo de probabilidades.

7 O método histórico-comparativo origina-se como subproduto do método comparativo. os chamados métodos mistos (mix methods), a exemplo do método de análise qualitativa comparativa (em inglês, qualitative comparative analysis ou QCA) (RAGIN, 2008). Diversos autores têm conjugado o uso de ferramentas estatísticas com a análise qualitativa de casos específicos e produzido estudos faseados que relacionam a análise inicial de muitos casos (large$-N$ ) com a investigação aprofundada de poucos ou apenas um caso (small- $N$ ou within-case analysis). Métodos como a análise de discurso e a análise de conteúdo também podem situar-se na conjunção entre perspectivas quantitativas e qualitativas (GOERTZ, 2017).

Por fim, ressalta-se o uso de métodos oriundos de outras disciplinas, como é o caso da etnografia. $\mathrm{O}$ uso de entrevistas não estruturadas (abertas) e de observação participativa e a construção de histórias de vida são técnicas de coleta de dados habitualmente associadas à Antropologia e à Geografia. Por meio desta abordagem, pesquisadores podem examinar como indivíduos e grupos humanos interpretam a realidade, rejeitando a existência de uma "realidade concreta e replicável". No curso do trabalho, o analista influencia e é ao mesmo tempo influenciado pela atividade de investigação.

\section{Debates contemporâneos}

As Relaçóes Internacionais enfrentam uma série de desafios no século XXI. Além da necessidade de compreender e explicar o difuso contexto internacional hodierno, a disciplina precisa transpor a histórica vinculação ao mundo ocidental e, particularmente, aos Estados Unidos. Ademais, é necessário avaliar criticamente se ainda faz sentido estudar as Relaçóes Internacionais de acordo com os grandes debates e/ou com áreas teóricas bem delimitadas, 
bem como repensar os avanços metodológicos realizados até o presente momento.

Em primeiro lugar, os estudiosos das Relações Internacionais encontram um mundo muito mais complexo do que durante o período de vigência do conflito bipolar. $\mathrm{O}$ mundo pós-Guerra Fria é marcado pela proliferação e aumento da importância de temas como o terrorismo, a saúde global, os direitos humanos, os fluxos de refugiados, a segurança cibernética e as tecnologias de informação e de comunicaçáo, as mudanças climáticas, a segurança alimentar e a não proliferação nuclear, entre outros. $\mathrm{O}$ declínio relativo dos Estados Unidos no âmbito econômico mas a sua ainda primazia militar, associado à mudança do centro de gravidade mundial para a Ásia, especialmente em função da ascensão de países como a China e a Índia, faz com que analistas de variadas tradiçôes teóricas questionem-se em que realidade estaríamos vivendo: se em um mundo unipolar, bipolar, multipolar, uni-multipolar (HUNTINGTON, 1999), multi-multipolar (FRIEDBERG, 1994), multimodal (WOMACK, 2016), multiplex (ACHARYA, 2014), pós-Americano (ZAKARIA, 2008), pós-ocidental (STUENKEL, 2016), policêntrico (DERICHS, 2014), G-zero (BREMMER, 2013), ou sem polaridades definidas (R. HAAS, 2008). Autores também dividem-se entre aqueles que acreditam na continuidade e resiliência da ordem liberal em vigor, como John Ikenberry (2018), e outros, como John Mearsheimer (2019), que observam a emergência de um mundo multipolar capitaneado por Estados Unidos e China e marcado por dinâmicas de conflito e cooperaçáo entre suas visóes de ordem internacional.

O segundo desafio enfrentado pelas Relaçóes Internacionais relaciona-se diretamente com essa incerteza. Uma vez que a configura- ção sistêmica se torna menos norte-americana e menos ocidental, como readequar a produçáo de conhecimento da disciplina? Como tornar as Relaçóes Internacionais realmente "internacionais"? Ainda dominada por publicaçóes no eixo anglo-saxão, a disciplina tem iniciado um lento processo de interlocuçáo com perspectivas e autores e autoras náo-ocidentais. Um dos principais elementos desse "encontro" é o fato de que há perspectivas fora do eixo transatlântico que questionam conceitos, teorias e epistemologias que foram criadas a partir do pensamento e da história ocidentais (ACHARYA; BUZAN, 2007; SIKKINK, 2014). Outra questão relevante é investigar se de fato existe um diálogo de iguais ou se vigora uma visão condescendente do eixo Europa-Estados Unidos, voltada náo para a troca de perspectivas, mas para a mera incorporação do que é "diferente" (TICKNER; WAEVER, 2009; BILGIN, 2008; ZARAKOL, 2011). Igualmente, deve-se evitar o risco de se criarem novas essencialidades, como "escolas nacionais" de Relaçôes Internacionais, e efetivamente pluralizar a produção do conhecimento.

Por fim, uma terceira vertente da agenda de investigação atual é sobre métodos e interdisciplinaridade. Por um lado, observa-se um crescimento do número de trabalhos que lidam com o realismo científico, o que contribui para o pluralismo metodológico e para a busca de um caminho intermediário entre métodos quantitativos e qualitativos. Processo semelhante tem ocorrido com autores que buscam ampliar a comunicação entre visóes racionalistas e reflexivistas. Por outro lado, a evolução das Relaçóes Internacionais tem-na aproximado de outras disciplinas, o que amplifica o seu escopo de atuação e favorece o surgimento de novas estratégias de investigação. 


\section{Referências}

ACHARYA, Amitav. The End of American World Order. Cambridge: Polity Press, 2014.

ACHARYA, Amitav; BUZAN, Barry. Why There is no non-Western International Relations Theory? An Introduction. International Relations of the Asia-Pacific, v. 7, n. 3, p. 287-331, 2007. Disponível em: https://academic.oup.com/ irap/article/17/3/341/3933493. Acesso em: 27 jun. 2021

BEACH, Derek; PEDERSEN, Rasmus Brun. Process-tracing Methods: Foundations and Guidelines. Michigan: University of Michigan Press, 2013.

BILGIN, Pinar. Thinking past 'Western' IR. Third World Quarterly, v. 29, n. 1, pp. 5-23, 2008. Disponível em: https:// www.jstor.org/stable/20455023. Acesso em 27 jun. 2021.

BREMMER, Ian. Every Nation for Itself: Winners and Losers in a G-Zero World. New York: Portfolio/Penguin, 2013

BROWN, Chris; AINLEY, Kirsten. Understanding International Relations. Nova York: Palgrave Macmillan, 2009.

BURCHILL, Scott; LINKLATER, Andrew. Introduction. In: BURCHILL, Scott; LINKLATER, Andrew; DEVETAK, Richard; DONNELLY, Jack; PATERSON, Matthew; REUS-SMIT, Christian; TRUE, Jacqui (eds.). Theories of International Relations. New York: Palgrave Macmillan, 2005, p. 12-13.

CHOWDHRY, Geeta; NAIR, Sheila (eds.). Power, Postcolonialism and International Relations: Reading Race, Gender, and Class. London and New York: Routledge, 2004.

DERICHS, Claudia. Asiatische Zeitenwende? Von der bipolaren zur polyzentrischen Weltordnung (Asian sea change? From the bipolar to a polycentric world order). Politische Vierteljahresschrift, v. 48, p. 41-66, 2014.

FRIEDBERG, Aaron L. Ripe for Rivalry: Prospects for Peace in a Multipolar Asia. International Security, v. 18, n. 3, p. 5-33, 1994. Disponível em: https://www.jstor.org/stable/2539204. Acesso em 27 jun. 2021.

GOERTZ, Gary. Multimethod Research, Causal Mechanisms, and Case Studies: an Integrated Approach. Princeton: Princeton University Press, 2017.

HAAS, Ernst B. The Uniting of Europe: Political, Social, and Economic Forces 1950-1957. Stanford: Stanford University Press, 1958.

HAAS, Richard N. The Age of Nonpolarity. Foreign Affairs, v. 87, n. 3, p. 44-56, 2008. Disponível em: https://www.foreignaffairs.com/articles/united-states/2008-05-03/age-nonpolarity. Acesso em 28 jun. 2021.

HUNTINGTON, Samuel. The Lonely Superpower. Foreign Affairs, v. 78, n. 2, p. 35-49, 1999. Disponível em: https:// www.foreignaffairs.com/articles/united-states/1999-03-01/lonely-superpower. Acesso em 28 jun. 2021.

IKENBERRY, John G. The End of Liberal International Order? International Affairs, v. 94, n. 1, p. 7-23, 2018. Disponível em: https://scholar.princeton.edu/sites/default/files/gji3/ files/inta94_1_2_241_ikenberry.pdf. Acesso em 28 jun. 2021. KANT, Immanuel. To Perpetual Peace: a Philosophical Sketch. Indiana: Hackett Publishing, 2003.
KEOHANE, Robert O.; NYE JR., Joseph. Power and Interdependence: World Politics in Transition. Boston: Little, Brown, 1977.

KEOHANE, Robert O.; MARTIN Lisa. Institutional Theory, Endogeneity, and Delegation. Working Paper 99-07. Weatherhead Center for International Affairs, Harvard University, Cambridge, p. 1-55, 1999.

MEARSHEIMER, John J. Bound to Fail: the Rise and Fall of the Liberal International Order. International Security, v. 43, n. 4, p. 7-50, 2019. Disponível em: https://www.belfercenter. org/publication/bound-fail-rise-and-fall-liberal-international-order. Acesso em 28 jun. 2021.

ONUF, Nicholas. World of Our Making: Rules and Rule in Social Theory and International Relations. Columbia: University of South Carolina Press, 1989.

RAGIN, Charles C. Redesigning Social Inquiry: Fuzzy Sets and Beyond. Chicago: University of Chicago Press, 2008.

SIKKINK, Kathryn. Latin American Countries as Norm Protagonists of the Idea of International Human Rights. Global Governance, v. 20, n. 3, p. 389-404, 2014. Disponível em: https://www.jstor.org/stable/24526221. Acesso em 29 jun. 2021.

STUENKEL, Oliver. Post-Western World: How Emerging Powers are Remaking Global Order. Cambridge: Polity Press, 2016.

TICKNER, Ann J, Gender in International Relations: Feminist Perspectives on Achieving Global Security. New York: Columbia University Press, 1992.

TICKNER, Arlene B.; WAEVER, Ole (eds.). International Relations Scholarship Around the World: Worlding Beyond the West. New York: Routledge, 2009.

ZAKARIA, Fareed. The Post-American World. New York: W. W. Norton \& Company, 2008.

ZARAKOL, Ayse. After Defeat: How the East Learned to Live with the West. Cambridge: Cambridge University Press, 2011.

WAEVER, Ole. Rise and Fall of the Inter-paradigm Debate. In SMITH, Steve; BOOTH, Ken; ZALEWSKI, Marysia (eds.). International Theory: Positivism and Beyond. Cambridge: Cambridge University Press, 1996, p. 149-185.

WALTZ, Kenneth N. Theory of International Politics. Illinois: Waveland Press, 2010.

WATSON, Adam. The Evolution of International Society. London: Routledge, 1992.

WENDT, Alexander E. The Agent-structure Problem in International Relations Theory. International Organization, v. 41, n. 3, p. 335-370, 1987. Disponível em: https://www.cambridge.org/core/ journals/international-organization/article/abs/agentstructure-problem-in-international-relations-theory/056581C7A48E985CCDCE5B32215B6139. Acesso em 29 jun. 2021.

WOMACK, Brantly. Asymmetry and International Relationships. Cambridge: Cambridge University Press, 2016. 